Brit J. industr. Med., 1948, 5, 26.

\title{
TOXIC EFFECTS OF NITROSO-METHYL URETHANE
}

\author{
BY
}

\section{F. WRIGLEY}

\author{
Roche Research Laboratories
}

(RECEIVED FOR PUBLICATION, OCTOBER 2, 1947)

Nitroso-METHYL URETHANE is mainly used as an intermediate in the preparation of diazomethane. It is a sweet-smelling, almost colourless, volatile liquid, boiling point $60^{\circ}$ C. at $10 \mathrm{~mm}$., and is capable of violent decomposition when overheated.

$$
\begin{gathered}
\mathrm{CH}_{8} \mathrm{~N}_{5} \mathrm{COOC}_{2} \mathrm{H}_{5} \\
\text { NO }
\end{gathered}
$$

\section{NITROSO-METHYL URETHANE}

. It is described by Pechmann (1895), who gives some details of its preparation and toxic effects. Pechmann refers to Klobbie (1890), and says, “ On account of the danger to the skin, lungs and eyes mentioned by Klobbie, the greatest care must be exercised when handling the nitrous compound. Klobbie has been good enough to inform me that the substance causes red, itching areas in the skin and blisters. Inspiration of the sweet-smelling vapour causes persistent bronchial catarrh and in addition, painful inflammation and disturbance of accommodation of the eyes. I myself suffered at first owing to the dangerous effect of the substance on the eyes and bronchi." Vanino (1922) warns against this substance, saying that the greatest care is necessary in working with the compound since it has a highly damaging action on the skin, lungs, and eyes.

\section{An Accident with Nitroso-Methyl Urethane}

This article describes the results of an accident in which several chemists were affected by nitroso-methyl urethane. At about 5 p.m. on the day of the accident a chemist was washing an ethereal solution of crude nitroso-methyl urethane with water in a large separating funnel when the stopper slipped a little and some of the contained liquid spilled on to his hand and the floor. He slid on the wet floor and, although he was working in a fume cupboard, the separating funnel and contents fell on the laboratory floor. The operator was splashed, particularly on the face and feet. The affected parts were washed on the spot and he was then seen by me. There was slight reddening of the conjunctivæ, together with erythematous patches on both feet. Further washing of the eyes and affected parts was carried out and emollients applied to the eyes and feet. Next day there was conjunctivitis of the right eye and some blistering of the toes and also of the skin in the region of the internal malleolus of the right foot. The following day the eye condition had resolved, but the patient had developed signs in his respiratory tract, complained of cough, and was hoarse. The blisters on the foot were still the same size, but the erythema was a little less. A few days later the chest symptoms were worse and his foot was unimproved. Up to this point he had been advised to rest, but living in lodgings made this difficult and it was not insisted upon.

In the meantime four other laboratory workers presented themselves for examination suffering from conjunctivitis in varying degrees of severity. In one of these the condition was extremely severe and accompanied by slight cough and general catarrh of the respiratory tract. Two others also were affected and treated by their own doctors. It appeared on interrogation that these people had walked through the area affected by the accident and the one complaining most had assisted the squad detailed to decontaminate the spot. With the exception of this case, which took about one week to clear, all the others were almost normal within two days.

One week after the incident the first patient was very much worse, the chest symptoms were more severe and the areas of inflammation on his foot increased. At this time he decided to return to his home and treatment was carried on by another doctor who made notes on his progress. The foot lesions developed to ulceration. It was not until 36 days after the accident that he was fit to get up, and he did not return to duty for a further three weeks.

\section{Comment}

All the people concerned in the handling of this substance had been warned of its possible toxic properties, but it had not been realized that slight exposure would result in irritation of exposed areas, 
nor was it appreciated that contact with the skin would result in such deep and extensive ulceration.

In an early article Pechmann (1894) describes the toxic effects of diazo-methane and these are similar to the symptoms and signs described above. He thought that the toxic effect of nitroso-methyl urethane was due to its transformation into diazomethane in the body. This is unlikely since strong alkali is necessary for the reaction. It is more probable that it is due to the toxic effect of the substance itself.

\section{REFERENCES}

Franchimont and Klobbie (1890). Ber. dtsch. Chem. Ges., 3, 62. Pechmann (1894). Ibid., 2, 1888. (1895). Ibid., 1, 856 .

Vanino (1922). "Praparative Chemie." 2, 183.

\section{BOOK REVIEWS}

\author{
ADVANCED INDUSTRIAL FIRST AID, 1947 \\ By R. A. Trevethick, M.B., Ch.B. \\ (Henry Garrett. Rotherham. 1947. Pp. 63. \\ No price given.)
}

In assessing the value of this booklet it is important to remember that it has been written, not as a text-book for the first-aider who is studying for an examination, but to impress the more experienced man with the value of common sense, simplicity, and speed in the practice of his art. Moreover, though it deals with the treatment of injuries which may occur in any factory, it is designed primarily for workers in the United Steel Companies and special emphasis is, therefore, laid on the treatment of major catastrophes, such as hæmorrhage and fractures. Four of the thirteen chapters are devoted to the latter subject and concise instructions are given for the treatment of each fracture. The simple method of applying a Thomas splint by two persons is described in detail, and advised for fractures of either femur or tibia.

In the chapter on hæmorrhage, it is refreshing to read that "the tourniquet is the most dangerous appliance which is used in first aid, and has caused more trouble than it has prevented." Sir Reginald Watson-Jones, in a foreword to this booklet, comments on this and says he would go even further and deny to any first-aider the right to use a tourniquet at all.

The author rightly points out, when discussing the treatment of burns, that the general, as opposed to the local treatment, is the most important thing in first aid. One must criticise, however, his instructions for treating burns due to strong acids or alkalis, in which it is felt that insufficient emphasis has been laid on the paramount importance of speed in treatment and in the use of adequate amounts of water to flood the affected area. The section on injuries to the eye might also have referred to the effects of acids and alkalis, and again impressed the first-aider with the necessity for speed in providing adequate treatment.

The booklet is concise and easy to read, and should be of value to experienced first-aiders in the steel industry, in giving them the latest methods of treatment, and helping them to discard the mass of elaborate detail which may allow a patient, in the words of Dr. Trevethick " to arrive in hospital with a leg beautifully bandaged and splinted-but dead."

A.L.P.

\section{DISEASES OF THE JOINTS AND RHEUMATISM By Kenneth Stone}

(William Heinemann. London. 1947. Price 30s.)

The author describes the book as intended for students who regret the omission from the medical curriculum of teaching in the "rheumatic diseases": and thinks that it should prove a helpful guide to those postgraduates who intend to engage in the special study and practice of this branch of medicine. There is no doubt that it achieves these aims. It is excellently printed on fine art paper and has many illustrations. The first part is orthodox and will prove a valuable reference guide. The author, however, seems to come unduly under French influence and quotes repeatedly from French sources ; one may wonder whether British and American views would not be more in sympathy with those of most workers in this country. It is stated that gold therapy is unquestionably the most effective therapeutic measure discovered so far for the treatment of rheumatoid arthritis, a view which would not be accepted by most general physicians ; this extreme view is exaggerated by the giving of little space and attention to other forms of treatment.

The second part of the book is devoted to what the author calls " vagotonic muscular rheumatism." Here he puts forward his own views on the causes of myalgia : views which are not generally accepted, though they are stimulating to read. It may be doubted, however, whether a book intended for medical students is the right place to propound these theories. Nevertheless, it is a good book which most doctors will find useful to possess.

K. M. A.P. 